\title{
El periodismo judicial en España
}

\author{
Dr. Javier Ronda Iglesias \\ Miembro del Grupo de Investigación en Estructura, Historia y Contenidos de la Comunicación \\ Periodista de Tribunales y Sucesos de Canal Sur Radio (Sevilla)
}

\begin{abstract}
RESUMEN
El periodismo judicial en España ha sido una de las grandes especialidades que ha experimentado una enorme transformación en los últimos años. Programas con noticias judiciales en radio y televisión, periodistas con un gran nivel de formación que escriben a diario noticias que son portada en la prensa. Son profesionales que saben descifrar el lenguaje jurídico y convertirlo en una noticia comprensible. Esta práctica del periodismo está considerada una de las que requiere una mayor especialización donde los periodistas de tribunales han pasado a ser ya un habitante de los juzgados de nuestro país.
\end{abstract}

\section{ABSTRAC}

In Spain, the justice journalism is very important in the last years. Every day the journalists going to the court to get news. This journalism need specialize in this matter, with words juridical.

Palabras claves: Periodismo/Judicial/Tribunales/Juzgados/Noticia judicial.

Key words: Journalism/Law/News/Court/Juridical/Justice/Specialized.

\section{1.- Concepto de periodismo de tribunales o periodismo judicial}

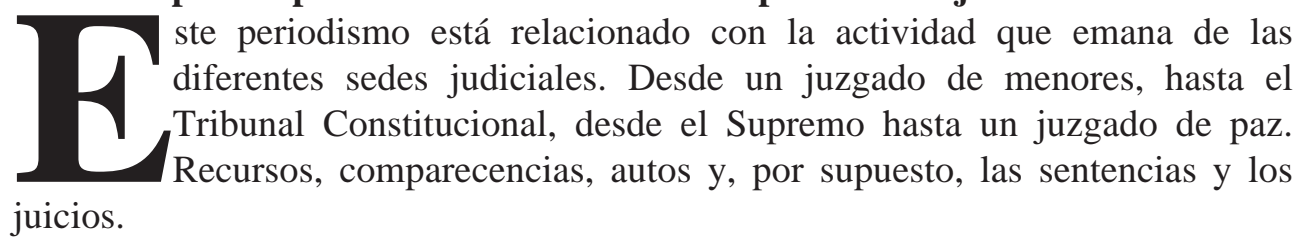

Los colectivos aludidos y las personas afectadas por una noticia son más sensibles cada día y traducen la inexactitud de lo contado en una lesión a bienes como el honor o el prestigio profesional fundamento de indemnizaciones millonarias. Se generalizan acciones judiciales y peticiones de rectificación.

El resultado es la exigencia de que el periodista sea conocedor e incluso experto de la materia tratada. Parecería que para realizar la crónica de una 
intervención quirúrgica fuera necesario tener nociones de medicina. Es una realidad que la mayor trascendencia de lo publicado en cualquier ámbito de la vida social genera la necesidad de mayor precisión y profesionalidad en el informador.

En los tribunales de justicia, a las razones expuestas y de validez general, deben añadirse otras.

En primer lugar, la naturaleza social del derecho como rama del saber humano. El derecho, a pesar de sus tecnicismos y sus obscuridades, se ocupa de solucionar conflictos entre individuos o colectividades.

En segundo lugar, la especialización es más acuciante en el campo del periodismo de tribunales por cuanto la mayor democratización de la sociedad aumenta su participación en el ejercicio y control de los poderes públicos, entre los que se encuentra el Poder Judicial.

En tercer lugar porque, sobre todo en el ámbito penal, la noticia judicial suscita una gran atención de la población, cualitativamente mayor que en otros campos.

$Y$ finalmente, el rigor informativo se hace necesario en el campo de los tribunales, en tanto que los errores pueden generar daños muy superiores a los que se producen en otras esferas.

La especialidad del periodismo de tribunales, ha tenido un interés creciente en los últimos tiempos no sólo en nuestro país, sino en la mayoría de nuestro entorno cultural.

Casos internacionales, como el de Pinochet, los crímenes en la antigua Yugoslavia y Milosevic, así como el interés que despierta el propio delito, se incrementa por la popularidad de los implicados. La sección de tribunales, habitualmente cercana a la página de sucesos, tiene derivaciones, cada día más frecuentes en otras secciones como política, sociedad o deportes, cultura, etc...

El periodismo judicial empieza a tener auge en España con la democracia y la Constitución de 1978. La posibilidad de seguir los juicios y los procesos judiciales hace que todos los medios de comunicación se interesen por los diferentes procesos y por las noticias que emanan desde los Juzgados o las Audiencias Provinciales, Tribunales Superiores de Justicia de cada Comunidad Autónoma, Tribunal Supremo, Tribunal Constitucional ${ }^{1}$. Desde una denuncia hasta una sentencia, un auto de prisión, la declaración de un testigo o el veredicto de un Tribunal del Jurado.

El periodismo judicial o periodismo de tribunales es aquel sector informativo, si se refiere al proceso penal, que incluye noticias relacionadas con hechos

1 Constitución Española,1978.Artículo 120.1 Las actuaciones judiciales serán públicas, con las excepciones que prevean las leyes de procedimiento. 2.El procedimiento será predominantemente oral, sobre todo en materia criminal. Las sentencias serán siempre motivadas y se pronunciarán en audiencia pública. 
delictivos denunciados en los tribunales de justicia. A partir de ahí abarca todas las actuaciones que pueden acabar en un juicio con su sentencia correspondiente de inocencia o culpabilidad. La información judicial aglutina diferentes campos, puede hacer referencia a noticias relacionadas con el narcotráfico, ecologismo, contrabando, corrupción, prevaricación, sectas, terrorismo, economía, espionaje, ejército, estafa, ámbito político, , evidentemente, el ámbito social con las habituales informaciones que hacen referencia a violadores, ladrones o asesinos, etc...

Es notorio que nos encontramos ante una de las secciones que tiene más interés para la opinión pública por su gran trascendencia y repercusión informativa frente a otras secciones más especializadas y que sólo interesan a parte de la sociedad.

Siempre se ha vinculado el periodismo de tribunales con el morbo, el amarillismo pero estas posibles prácticas periodísticas quedan algo lejanas si se trata de medios públicos y privados con rigor y "serios". El sensacionalismo en el periodismo de tribunales corresponde a veces a medios de comunicación muy pendientes de sus audiencias y de la publicidad más que del principio informativo de contar esta noticia de tribunales.

Del concepto más genérico definido como Periodismo de Tribunales, se pueden distinguir categorías cercanas que en ocasiones, incluso, se mezclan o se confunden, como el periodismo de sucesos, el periodismo de investigación y finalmente el que puede denominarse periodismo de los tribunales, que se refiere a la actividad de la familia judicial como colectivo: una huelga de funcionarios de justicia, el nombramiento de un fiscal jefe, o el ascenso de un juez a magistrado.

\section{2.- El escenario de la noticia judicial}

No son campos de fútbol, ni sedes de partidos políticos o un ayuntamiento. No suele haber ruedas de prensa por norma, la información de tribunales discurre por despachos de abogados, pasillos de juzgados, asistencia a juicios, esperas en las puertas del juzgado de guardia. Por estos derroteros se mueve el periodista de tribunales con un trabajo individual y sin fuentes informativas oficiales y sin convocatorias de ruedas de prensa o comunicados para los medios. Así es el periodismo de tribunales diferente al resto.

La proliferación de estos escenarios, las sedes judiciales, requiere la presencia de informadores y ha generado en los últimos años que haya más periodistas capacitados para cubrir información de tribunales. De todas formas, es posible que en alguna ocasión algún redactor novel se haya visto en la difícil situación de cubrir una información de tribunales, sin apenas tener conocimientos elementales sobre las reglas que regulan un proceso judicial. Puede incluso que ni siquiera haya tenido la oportunidad de conocerlas. A pesar de ello debe hacer su crónica sin decepcionar a sus superiores en la empresa y, a la vez, sin provocar una demanda judicial contra su medio de comunicación. 
Para entender mejor la situación podríamos imaginar las dificultades de un periodista que tuviera que hacer la crónica de un partido de tenis sin conocer las reglas sobre el saque, el sistema de puntuación o el objetivo final del juego. Seguramente podría dar el nombre del ganador, a partir de interpretar los gestos de cada jugador al acabar el partido, pero poco más puede esperarse del contenido de sus comentarios. Sin convertirlo en un especialista de ese deporte, para contar en una simple crónica lo que ha ocurrido, resulta obvio que necesita conocer las reglas básicas del juego.

Problemas para los accesos a las sedes judiciales con el material indispensable para informar como una grabadora o una cámara de televisión o de fotos.

\subsection{El Poder Jurisdiccional y las diferentes jurisdicciones.}

Debemos partir de la idea de que detrás de un proceso judicial siempre encontramos una situación de conflicto entre varios miembros de una determinada comunidad social. Los ciudadanos con intereses enfrentados acceden a los tribunales cuando no consiguen resolver sus diferencias amistosamente. Es un dicho que recoge la sabiduría popular que "más vale un mal arreglo que un buen pleito". Cuando el arreglo o acuerdo no es posible, los implicados en el conflicto llegan a los tribunales: formalizan su conflicto. En algunos casos, en el ámbito civil y laboral, la ley establece como primera obligación del juez, precisamente, la de provocar o facilitar ese acuerdo que evite el juicio.

El conflicto es el presupuesto del proceso y su resolución o superación su objetivo último. Conflicto definido como una controversia entre ciudadanos o instituciones con intereses enfrentados que, en tanto que no alcanza su disolución por acuerdo o composición de sus protagonistas, altera el normal discurrir de la vida social. Y resolución del conflicto que se produce cuando las partes enfrentadas, a partir de la decisión del juez, se conforman y superan sus diferencias.

El Poder Jurisdiccional consiste en la facultad de determinados órganos del Estado para conocer y dar solución a una situación social problemática. Cuando se dice que el Poder Jurisdiccional está sujeto al Principio de Legalidad, se advierte que la solución final que mediante la resolución se impone a las partes en conflicto, debe estar de acuerdo con unas reglas prefijadas (leyes). Estas normas vinculan a los órganos jurisdiccionales no sólo en la determinación de la resolución final que establezcan, sino también respecto al modo de llegar a la misma.

El Poder Jurisdiccional, como poder del Estado, se rige por el principio de unidad $^{2}$. Pero la distinta naturaleza de los conflictos, determina como veremos diferentes clases o categorías de órdenes jurisdiccionales. El periodista debe pre-

2 El artículo. 117.5 de la C.E. dice que el principio de unidad jurisdiccional es la base de la organización y funcionamiento de los Tribunales. 
guntarse en primer lugar, al informar de un asunto judicial, de qué jurisdicción se trata o, lo que es lo mismo, qué clase de conflicto se va a resolver.

\section{Jurisdicción Civil.}

Un pleito civil alberga un debate entre particulares sobre cuestiones que afectan exclusivamente a sus intereses y, por tanto, de naturaleza estrictamente privada: el vecino de arriba ha mojado y estropeado el techo de mi salón, se niega a repararlo; la parcela colindante ha extendido su linde invadiendo la mía. Debe advertirse que también pueden ser parte de un asunto civil, instituciones públicas, como un ayuntamiento por ejemplo, pero, en todo caso defendiendo cuestiones de naturaleza privada.

En el seno de la jurisdicción civil se incluyen también las reclamaciones de quien entiende que se ha ofendido su honor o el derecho a su propia imagen, interesando una indemnización. Así la actriz que reclama al medio que publica una foto en top less en la playa.

Y, también, dentro de la jurisdicción civil se incluyen todas las cuestiones referidas al ámbito familiar. Los procesos de separación, divorcio y nulidad de los matrimonios, las reclamaciones o impugnaciones de la paternidad o maternidad, entre otros. Si bien caracterizábamos la jurisdicción civil por ocuparse de la resolución de conflictos de intereses entre particulares, cuando en el ámbito del derecho de familia la controversia afecta al estado civil o puede afectar a menores, se vez afectados intereses públicos,. Por eso, en estos pleitos civiles participa el Ministerio Fiscal.

\section{Jurisdicción Penal.}

El caso judicial con trascendencia pública frecuentemente pertenece al ámbito de la jurisdicción penal. En estos casos subyace un conflicto entre uno o varios miembros de la comunidad y el conjunto social. Se ha producido un hecho que, al haber puesto en cuestión alguno de los valores básicos de la comunidad, (por ejemplo la conservación de la vida humana, en el delito de homicidio) convulsiona los cimientos éticos sobre los que se asienta la convivencia social. Quien pueda ser autor de ese hecho se ha enfrentado así al conjunto de la sociedad. Cuando una persona mata a otra, no sólo se establece un conflicto entre el autor del hecho y los herederos de la víctima. También, y sobre todo, se establece un enfrentamiento entre quien mató y el resto de la comunidad que tiene como regla esencial la de que nadie puede quitar la vida a un conciudadano. Y éste es el supuesto previo a la intervención de la jurisdicción penal. El delito puede definirse como un acto que pone en cuestión un principio, que por una comunidad social a través de la ley ha sido declarado como esencial, básico, mínimo ético para todos, inquebrantable. La comisión de un delito da lugar a que toda la comunidad se tambalee por el golpe sufrido en uno de sus cimientos. El orden jurisdiccional penal pretende resolver un 
conflicto entre la comunidad y uno o varios de sus miembros, para determinar si han agredido con su actuación a toda la comunidad. Las notas propias de este conflicto vienen asociadas a la gravedad de los hechos, la conmoción social, la contundencia en la respuesta. Estas notas hacen especialmente periodística esta jurisdicción.

Dentro del proceso penal se trata de determinar si un hecho, incluido en el catalogo legal de delitos, ha sido realizado por una persona. Siendo objetivo esencial del proceso penal moderno, también, que en el esclarecimiento no se vean afectados la dignidad y los derechos fundamentales del investigado.

\section{Jurisdicción laboral}

La relación entre quien presta sus servicios en favor de otra persona y la que se beneficia de ellos, situada inicialmente dentro del derecho civil, se ha masificado a partir de las revoluciones industriales. Aparece ahora una relación jurídica idéntica en grandes masas de trabajadores, vinculados por la misma a los empresarios. Y la sociedad moderna avanzada entiende que en esa relación deben observarse principios de justicia que están por encima del estricto juego de los intereses individualmente considerados. En el seno de esta relación laboral se producen conflictos conocidos por todos: despidos procedentes o no, incapacidades laborales, derecho al descanso semanal, guardias y retribuciones de los servicios, etc...

También los conflictos en éste ámbito tiene unas características propias que justifican unas normas procesales distintas ante unos jueces específicamente dedicadas a ellas. Así surge la jurisdicción laboral. Aparecen asuntos de esta jurisdicción ante la opinión pública en función de la popularidad del implicado, sobre todo en casos de deportistas, toreros, en supuestos de grandes conflictos en las páginas de economía o laboral.

\section{Jurisdicción Contencioso-administrativa}

En las distintas actuaciones que toda esa nueva maquinaria burocrática lleva a cabo pueden plantearse situaciones de conflicto entre sus órganos o secciones y los ciudadanos, o incluso entre sí. Este grupo de conflictos tiene tantas características propias que hacen necesario un entorno jurisdiccional distinto y adecuado a ellas. Es decir, hacen necesario un ámbito jurisdiccional propio, denominado Contencioso-Administrativo. El Ayuntamiento no me da licencia para construir y creo que tengo derecho, un administrado considera que la multa de tráfico es injusta y pide al tribunal que revise la misma o alguien tiene derecho a una subvención que le ha sido denegada. 


\section{Jurisdicción Militar}

La organización del ejercito, por su interés público y por las características específicas de las reglas propias que regulan su organización y funcionamiento, dan lugar a una jurisdicción propia también ${ }^{3}$. Por ejemplo los juzgados togados militares de cada zona.

\section{3.- El seguimiento informativo de un proceso penal}

La actuación de los tribunales, como expresión de uno de los poderes del Estado, tiene vocación de ser pública. La publicidad es consustancial a la propia función jurisdiccional. En cualquier caso, en una u otra jurisdicción, el poder jurisdiccional tiene una naturaleza pública y toda su actuación se proyecta sobre la comunidad. Desde una concepción democrática del poder, éste debe ser transparente. La publicidad se transforma en un medio de control, medida de legitimidad. Son conocidas las palabras del político ilustrado Mirabeau: "dadme el Juez que os plazca: parcial, venal, incluso mi enemigo; poco importa con tal de que no pueda hacer nada sino de cara al público".

El proceso judicial nace de una situación de conflicto social y pretende ofrecer una solución, para que la comunidad recupere su anterior situación de tranquilidad. Cualquiera que sea su naturaleza, el proceso tiene una dimensión social y, sólo cumple su finalidad si se proyecta sobre la sociedad. La resolución judicial explica a todos cómo se ha resuelto la controversia. En tanto que manifiesta el funcionamiento normal de las instituciones, genera paz social. En primer lugar porque concluye civilizadamente el inicial enfrentamiento, pone fin a la disputa, señala el final del conflicto. Y, en segundo lugar, porque esa decisión final puede ser conocida por todos. Por tanto, las resoluciones judiciales sólo cumplen plenamente sus misiones propias si son conocidas por todos.

Por otra parte, la decisión cuando ha cumplido unas normas previamente establecidas, se impone a los litigantes y a toda la sociedad. Es expresión de un poder del Estado y eso quiere decir que las decisiones de los tribunales se imponen a todos. Su cumplimiento no es opcional o voluntario, sino obligatorio. Evidentemente, para ello deben ser conocidas por todos, pues no puede imponerse una decisión si no es comunicada a quien debe acatarla o cumplirla. De forma expresiva, en un curso entre jueces sobre el lenguaje jurídico decía la magistrada Manuela Carmena "para que nos obedezcan es fundamental que nos entiendan".

En nuestro derecho este principio de publicidad alcanza rango de norma constitucional ${ }^{4}$.

3 El artículo 117 CE establece también que la Ley regulará el ejercicio de la jurisdicción militar en el ámbito estrictamente castrense y en los supuestos de estado de sitio. De acuerdo con los principios de la Constitución.

4 Artículo 120.1 de la C.E.: "Las actuaciones judiciales serán públicas, con las excepciones que prevean las leyes de procedimiento". 
En las sociedades modernas, los medios de comunicación de masas son el instrumento idóneo para trasladar cualquier información al conjunto social. Los medios son el instrumento de realización efectiva del principio de publicidad. Cumplen así una función social con importancia de primer orden. En relación con el Poder Judicial, esta misión se concreta a través del periodismo de tribunales.

La cuestión de cómo se hacen públicas las resoluciones judiciales, a través de qué medios, con qué eficacia, no ha sido objeto de suficiente estudio. El principio de publicidad exige el acceso libre y gratuito de cualquier ciudadano a las resoluciones judiciales. Por contra, hoy el acceso al conocimiento de las decisiones de los más altos tribunales no sólo no es fácil para los propios juristas, sino que ni siquiera es gratuita. Entre las funciones que la ley atribuye al tribunal está la de hacer pública la sentencia. Sin embargo, en la actualidad para conocer las resoluciones del Tribunal Supremo, el Tribunal Constitucional o las Audiencias Provinciales, es necesario subscribirse a alguna de las colecciones jurisprudenciales que están en el mercado. La reflexión nos llevaría fuera de los límites de este trabajo. Puede decirse que esta dificultad de acceso a resoluciones judiciales carece de justificación en nuestros días.

La plaza pública en las sociedades modernas son los medios de masas. La trascendencia pública de los conflictos está en relación directa con la importancia social del valor que está en discusión. Por ello, los asuntos penales son los que más presencia encuentran en los medios de comunicación.

Los valores sociales más importantes (la vida, la integridad física, la libertad en sus diferentes vertientes, etc...), cuando sufren ataques directos (asesinatos, lesiones, agresiones sexuales, secuestros) generan un conflicto que se resuelve a través de un procedimiento penal. Como los valores en cuestión son de primer orden, los ataques a los mismos dan lugar a hechos de enorme repercusión social. Esto explica la conmoción social que se produce a partir de asesinatos múltiples, de agresiones sexuales a menores. En consecuencia, los procedimientos penales tienen un interés periodístico de primer orden. Los demás órdenes jurisdiccionales tienen un interés informativo mucho menor, excepto cuando se trata de asuntos en donde se encuentra implicado algún personaje de relevancia publica o afecta a un número de personas elevado, dando lugar a movilizaciones o actos de adhesión o protesta de los afectados.

El periodismo de tribunales no sólo debe dar a conocer las resoluciones judiciales sino que debe explicarlas, hacerlas comprensibles para el conjunto de la ciudadanía. Para cumplir esta finalidad tiene que saber traducir el opaco y a veces oscuro lenguaje jurídico, sin merma de su contenido y respetando con rigor su significado. 


\section{4.- Fuentes del periodismo judicial}

La información judicial es muy complicada, técnica y cerrada vista desde el exterior. Independientemente de la especialización, los profesionales de la comunicación suelen tener numerosos problemas para acudir a las fuentes para confirmar o constatar una noticia. Es el verdadero problema y caballo de batalla de esta especialización periodística. Evidentemente es más fácil que un líder sindical, un director general, un alcalde o un cantante puedan ofrecer una entrevista o se pueda utilizar como fuente porque es relativamente más fácil, que un juez, un fiscal o un presunto homicida que está en la cárcel.

El periodista de tribunales ha de tener bastante cuidado para confirmar su información si no quiere acabar con una «querella». Es muy grave dar una noticia equivocada sobre la identidad de un violador, un asesino o un estafador, o el nombre de una empresa que ha cometido un delito ecológico. El impacto es menor e incluso el daño, si se informa de forma errónea sobre si se van a pintar los autobuses de color amarillo en vez de color verde, si el alcalde se va a reunir con el presidente de la diputación en lugar del presidente de la Comunidad o si el IPC ha subido un $1 \%$ en vez de un $2 \%$. Evidentemente estos errores en una información periodística también tendrían su importancia pero a la vista está que el impacto y la trascendencia serían casi siempre mayor en una información judicial: «Han absuelto al violador» cuando lo han condenado a 20 años de cárcel, «el juzgado investiga un vertido de cianuro» en vez de un vertido de alpechín.

\subsection{Los Jueces y magistrados.}

Es uno de los responsables de los juzgados o salas. Suele tener toda la información pero ofrece muy poca a los medios de comunicación, o ninguna, por su cometido como juez. No suele ser una buena fuente, ya que su celo profesional y el deber de mantener secretas las actuaciones y su gran ocupación diaria y poco contacto con los periodistas le convierten en una fuente casi inaccesible. Sin embargo, algunas veces dependiendo del juez o magistrado puede dar una instrucción a un funcionario para que le de al periodista la información requerida. Si se ha notificado una sentencia que nos interesa, por ejemplo. Un juez o un magistrado casi nunca recibe a un periodista en su despacho. No suele ser una buena fuente informativa porque no ofreces detalles y lo mejor es no perder tiempo en intentar conseguir hablar con él, salvo excepciones.

\subsection{Los secretarios.}

Como fedatario, es el que conoce mejor, junto a los jueces y magistrados, cómo va un procedimiento. Si han citado a imputados a declarar, cuándo lo van a hacer, qué día, la hora, si ya el juez ha redactado la sentencia, si se archiva la causa, si se ha depositado una fianza, si ha declarado un testigo, etc.. Dispone de información útil para el periodista judicial pero también es difícil acceder a él. No 
obstante, suele ayudar en algunos casos a los periodistas y sirve como «orientador» en numerosas ocasiones. Suele atender al periodista y es una buena fuente informativa más fácil y accesible que el propio juez, y que un periodista judicial debe tener.

\subsection{Los fiscales.}

El Estatuto Orgánico del Ministerio Fiscal, que es su norma reguladora, relaciona al Fiscal con la información a la opinión pública de los acontecimientos judiciales. ${ }^{5}$ Es un colectivo que suele tener bastantes relaciones con los profesionales de la información. Como representantes del Ministerio Público suelen colaborar y ayudar casi siempre a los periodistas. El escrito de acusación en un procedimiento, con el que se abre el juicio oral y, por tanto la fase pública del proceso, suele ser el documento al que tiene acceso un periodista para conocer un caso. El fiscal no lo suele ofrecer al periodista pero en la sala, juzgado, o uno de los abogados personados suele proporcionarlo al informador. El escrito de acusación donde por ejemplo el fiscal acusa de estafa, agresión sexual, homicidio, apropiación indebida, etc... es suficiente inicialmente para que el periodista judicial pueda construir una información. Para el periodista de prensa o agencia informativa es muy útil, no tanto para la radio o televisión porque en raras ocasiones suelen conceder una entrevista o quieren ponerse delante de un micrófono para hablar de un caso. Sin embargo, es una de las mejores fuentes informativas que tiene un periodista de tribunales. Su colaboración es fundamental y de gran utilidad para los profesionales de la información.

\subsection{Los abogados.}

Sin duda alguna es la mejor fuente informativa del periodista judicial. Tienen acceso a las actuaciones y son los que suelen informar a los periodistas. Su colaboración para difundir una información judicial es total. También hay que tener en cuenta que el abogado cuando ejerce la acusación suele ser más proclive a colaborar con el periodista. Cuando ejerce la defensa no tanto. Por ejemplo, el letrado que representa a una mujer violada siempre estará dispuesto a hablar con un periodista para defender a su clienta. El abogado del acusado, del violador, quizás no quiera hacer declaraciones y remita al periodista al seguimiento del juicio o de las actuaciones. Aunque cada caso es distinto evidentemente, los abogados constituyen el colectivo más grande de la «familia judicial» y todo depende del letrado. Suelen colaborar, preguntan a su cliente, no suelen poner

5 Estatuto Orgánico del Ministerio Fiscal, Ley 50/1981 de 30 de diciembre, artículo. 4. 5 "El Ministerio Fiscal, para el ejercicio de las funciones encomendadas podrá : (...)5. Informar a la opinión pública de los acontecimientos que se produzcan, siempre en el ámbito de su competencia y con respeto al secreto del sumario". 
problemas para que se les grabe en la radio o televisión y son los que aparecen más y tienen mayor "tiempo de pantalla" tanto en la prensa, como en la radio o televisión y, por supuesto, en las agencias de noticias.

\subsection{La Policía.}

Como eslabón entre el suceso y el paso al juzgado del caso, es muy importante como fuente informativa. La Policía cuenta con un gabinete de prensa como Dirección General de la Policía, también en las Jefaturas autonómicas o Comisarías provinciales suele haber un servicio de prensa. Realizan notas de prensa, cuando el suceso ha pasado y el caso ya se encuentra en el juzgado. Como fuente es importante, y constituye siempre la versión oficial. Funcionan con notas de prensa o ruedas de prensa en ocasiones especiales.

En el nivel particular los agentes no suelen información a los periodistas, los grupos tienen unos jefes, como homicidios, atraco, extranjero y siempre nos remitirá al gabinete de prensa. Su jurisdicción habitual hay que recordar que son las grandes ciudades y localidades, representa un $30 \%$ del territorio nacional.

\subsection{La Guardia Civil.}

Igual que la Policía funciona con gabinetes de prensa, hay uno en la Dirección General de la Guardia Civil, otro en cada zona (Comunidad Autónoma) y en cada Comandancia suele haber designada una persona de contacto. Su lugar de actuación suele ser en los pueblos aunque depende del caso o las investigaciones. Su demarcación es un $70 \%$ del territorio español aproximadamente. Como los policías, los guardias civiles no informan a los medios de comunicación salvo el portavoz o persona autorizada. También realizan ruedas de prensa o envían notas de prensa a los medios cuando la investigación ha terminado y los detenidos están ya a disposición judicial.

\subsection{La Unidad Adscrita de la Policía Judicial.}

Considerada la policía de los jueces, la que trabaja con ellos para investigar, no responde ni mucho menos a la capacidad que tiene en el modelo norteamericano la Oficina del Fiscal con sus detectives. Hay dos unidades adscritas de la policía judicial, una de la Guardia Civil y otra de la Policía. Tampoco es una buena fuente, suelen ser pocos efectivos, se encuentran en las dependencias de los juzgados y nunca dan información de sus investigaciones, se deben al secreto profesional. Sería una buena fuente informativa.

\subsection{Los denunciantes y denunciados.}

Es una buena fuente informativa para un periodista. Suelen acudir en numerosas ocasiones a los medios de comunicación y a los periodistas para que les ayuden en su caso. Suelen entregar la documentación y no hay problemas en que 
se le pueda hacer una entrevista para la radio o televisión. Algunas veces ven en los medios de comunicación la última oportunidad para resolver su problema judicial. Un periodista de tribunales puede divisar a estas personas con bastante facilidad. Suelen ser muy dialogantes pero el periodista debe ser muy selectivo, porque para el denunciante o denunciado su caso o asunto siempre será el más grave del mundo, pero a lo mejor no tiene interés informativo. También se puede perder tiempo con estas personas, pero es aconsejable atenderlas siempre porque el periodista puede encontrar casos interesantes en algunas ocasiones.

El prototipo es la persona que va a solicitar abogado de oficio, la madre que pide que le den la libertad condicional a su hijo ingresado en prisión y que tiene una grave enfermedad, suele ser bastantes casos de trascendencia social. En general suele ser una buena fuente informativa.

\subsection{Informador anónimo.}

Como parte interesada, es una fuente informativa que ofrecerá al periodista la información que más le convenga. No se identifica, y suele contactar con el periodista de forma telefónica o enviando una carta. Podría revelar información sobre torturas a un preso, una estafa de una empresa, abuso de un superior, etc..., pone en la pista al periodista para que investigue. Suelen ser informaciones «muy comprometidas» y por lo tanto en este caso es importante tener toda la información posible y contrastar al máximo la noticia antes de difundirla. Nuestro único respaldo será nuestro propio trabajo e investigación del caso. Puede ser una buena fuente informativa, pero de entrada como consejo «hay que poner en cuarentena su información».

\subsection{Ciudadano.}

Es una fuente a tener en cuenta sobre todo en el denominado «periodismo de denuncia». Suelen ponerse en contacto con los medios de comunicación para denunciar ante el periodista hechos de índole doméstico o vecindad. Es típica la llamada del vecino que aguanta el ruido de una discoteca, ya ha denunciado la comunidad en el juzgado al dueño del establecimiento, la policía va de vez en cuando se baja el volumen pero de momento el local sigue abierto. El ciudadano no ha denunciado directamente, pero está muy pendiente del caso. Suelen llamar a un medio de comunicación cuando la situación es extrema.

\section{5.- El periodismo de tribunales y el acceso a las sedes judiciales}

En la actualidad, los tribunales se han convertido en una «mina informativa» para los medios de comunicación españoles donde, además de los grandes y conocidos juicios, existen otras historias personales y de interés que serían noticia si el periodista las conociera. Es cierto que la información judicial es compleja, y todavía resulta más difícil cuando hay que convertir «el lenguaje jurídico, en 
lenguaje periodístico» y que sea entendido por el mayor número de componentes del público o audiencia.

Los periodistas deportivos tienen como lugar de trabajo los campos de fútbol; los de política, los parlamentos o las sedes de los diferentes partidos; los de cultura, el teatro o la ópera; y los de periodismo de tribunales, los juzgados pero con dificultades ${ }^{6}$.

El escenario para el periodista de tribunales es complejo, restrictivo y poco afable para desarrollar su función informativa. Los famosos, los políticos, los deportistas, entre otros, cuando acuden al juzgado son objetivo periodístico, desde diferentes perspectivas: amarillismo para ciertos programas televisivos o rigor informativos para otro medios que sólo se ciñen a la noticia.

Con todo este panorama nos encontramos, por ejemplo con las reglas dictadas por el Tribunal Superior de Justicia de Andalucía, que fueron valoradas de forma poco favorable desde diversos colectivos de los profesionales de los medios de información, cuando se anunciaron en los preámbulos de la celebración del famoso juicio del Caso Arny, celebrado en Sevilla por corrupción de menores. Éste es el acuerdo íntegro del Tribunal Superior de Justicia de Andalucía (TSJA).

\section{REGLAS SOBRE EL ACCESO DE LOS MEDIOS DE COMUNICACIÓN SOCIAL A LAS SEDES JUDICIALES}

"El acceso de los medios de comunicación a las sedes de los órganos judiciales se somete a las siguientes reglas:

1. No se permitirá la introducción y utilización de cámaras de televisión, de vídeo, fotográficas o cualquier otro instrumento de reproducción o transmisión de la voz o la imagen, en las sedes judiciales, con las siguientes excepciones:

a) Previa autorización expresa, se podrá permitir el acceso de tales medios técnicos para actos gubernativos solemnes y, en el ámbito de la sede del Tribunal Superior de Justicia, para ejercicio por la Oficina de Prensa de la Presidencia de dicho Tribunal de sus funciones. Deberá acreditarse en esos casos la existencia de

6 «En los dos edificios que albergan (los jugados de primera instancia, instrucción y penal) de Madrid en la Plaza de Castilla, los periodistas entramos como cualquier ciudadano, esperamos como cualquier ciudadano y pasamos los correspondientes controles como cualquier ciudadano. Hace unos años el periodista tenía un carné para que no tuvieron que soportar la grandes filas que se formaban en la puerta. Fue peor el remedio que la enfermedad : Los vigilantes jurados, en cuanto veían un carné de periodista, preguntaban adónde ibas y con quién querías hablar, te advertían de que no podías utilizar una grabadora..." Conferencia de Agustín Yanel:" Demasiadas carencias para un derecho fundamental" redactor de tribunales del diario El Mundo en el Encuentro entre jueces y periodistas (Federación de Asociaciones de la Prensa FAPE y CGPJ Consejo General del Poder Judicial), Madrid, octubre de 1998. 
dicha autorización expresa.

b) En el caso de que el Ministerio Fiscal este ubicado en las sedes judiciales, se estará a las instrucciones dadas por este respecto a sus dependencias en orden a al desarrollo de su tarea de informar a la opinión pública de los acontecimientos que se produzcan en el ámbito de su competencia. De exigirse en esas instrucciones autorización expresa, se deberá igualmente acreditar ésta.

2. Para el ordenado desarrollo de su función, los profesionales de la información acreditarán su condición de tales ante los servicios de seguridad de las distintas sedes judiciales, que, en tal caso, les entregarán credencial acreditativa de su profesión.

Por la Sala de Gobierno del Tribunal Superior de Justicia se aprobará el modelo de tal credencial.

3. Cuando la de las dependencias judiciales no permita la presencia de todos los que lo deseen, los profesionales de la información tendrán preferencia para acceso a las mismas.

4. Corresponde velar por el cumplimiento de las reglas establecidas en los apartados anteriores a las siguientes Autoridades:

1. Al presidente del tribunal superior de justicia en la sede del tribunal y aunque ésta se comparta con otros órganos judiciales.

2. A los presidentes de las audiencias provinciales, en las sedes de éstas, aunque sean comunes a órganos jurisdiccionales unipersonales.

No obstante lo anterior, si la Audiencia Provincial y alguna de las Salas del Tribunal Superior de Justicia comparten el mismo edificio, será el Presidente de la Sala quien ostente la representación del Poder Judicial y en el ámbito de la misma a quien deba corresponder tal atribución.

A los decanos y en el caso de que varios órganos unipersonales se ubiquen en que las mismas dependencias.

A los titulares de los órganos unipersonales de los demás casos.

5. En el ejercicio de su policía de estrados, los jueces y tribunales podrán ampliar, restringir o condicionar la publicidad de los juicios, permitiendo incluso el acceso de medios audiovisuales de información, debiendo en tal caso comunicarlo a la Sala de Gobierno para su conocimiento, y a la autoridad encargada de velar por la observancia de estas reglas a fin de que adopte las medidas oportunas para garantizar su debido cumplimiento.

6. Estas normas entrarán en vigor el 1 de junio del corriente en toda las sedes judiciales del territorio andaluz. (1996)

7. Para su conocimiento difusión, está Acuerdo ser remitida por los canales ordinarios a los titulares de todo los órganos judiciales del territorio, y por los máximos responsables de su cumplimiento en cada provincia se hará saber de modo fehaciente y dejando la debida constancia, a todos los directores de los medios comunicación de la misma. 
Particípese el presente Acuerdo, para su conocimiento y difusión, al Consejo General del Poder Judicial y a los órganos judiciales y medios de comunicación del territorio, a de llegándose en la oficina de prensa de la presidencia la difusión en los medios de comunicación acreditados en Granada y en los Iltmos. Sres. Presidentes y Decanos del resto del territorio, conforme a lo acordado".

Por lo que respecta a la postura del Consejo General del Poder Judicial sobre la publicidad de las actuaciones judiciales, es de interés las dos cuestiones siguientes:

a) Oficinas de Información.

Por Acuerdo de 5 de noviembre de 1986, el Pleno del CGPJ, «observando con creciente preocupación la actitud de diversos jueces y magistrados que en medios de comunicación estatales y privados realizan manifestaciones en relación con materias sometidas a su potestad jurisdiccional», recaba de todos los miembros integrantes del Poder Judicial «la eliminación de tales actitudes y manifestaciones públicas, que, aun siendo minoritarias, pueden comprometer la independencia judicial» y, «atendiendo a la demanda social de información en problemas de que conoce la Administración de Justicia, así como al lícito derecho de los ciudadanos de recibir veraz y objetiva información de tales materias, el Consejo emprende la puesta en marcha de Servicios u Oficinas de Información, en determinados órganos jurisdiccionales, con objeto de garantizar a todos los ciudadanos esa veraz información».

b) Acceso de los medios de comunicación a las Salas de Justicia.

Con fecha 12 de septiembre de 1995, la Sala de Gobierno del Tribunal Supremo aprobó unas Normas sobre acceso al palacio sede del Tribunal Supremo, de las cuales la sexta, relativa al Acceso al Palacio de los medios de comunicación social, era del tenor siguiente:

«1. En el Acto de Apertura del Año Judicial, tomas de posesión y demás actos gubernativos solemnes se facilitará el acceso de los medios de comunicación social en general, y de las televisiones públicas y privadas en particular, que lo soliciten de la Secretaría de Gobierno, que extenderá las pertinentes acreditaciones y tomará las disposiciones necesarias para que los expresados medios puedan cumplir su misión informativa sin menoscabo del acto que haya de celebrarse. Lo anterior se entiende sin perjuicio de las competencias propias de los Servicios de Seguridad. 2. Fuera de los mencionados actos, el acceso de los medios de comunicación al Palacio requerirá autorización expresa de la Presidencia del Tribunal Supremo.-

3. No se permitirá el acceso de los indicados medios con cámaras fotográficas o de televisión a juicios o vistas en ninguna de las Salas».

Tras recibir quejas de la Asociación de Escritores y Periodistas Independientes y de un grupo de «periodistas que habitualmente cubrimos la información de tribunales», la Sala de Gobierno del Tribunal Supremo, con fecha 25 de septiembre, sustituyó la norma transcrita por la siguiente:

«Acceso al Palacio de los medios de comunicación social.- 1. Los profesionales de los medios de comunicación social podrán acceder a los actos jurisdiccionales o gubernativos que se celebren en régimen de audiencia pública con sujeción a las normas generales de seguridad. La Secretaría de Gobierno extenderá las oportunas acreditaciones e identificaciones. Cuando en un acto de la naturaleza de los expresados la capacidad de la Sala o local no fuere bastante para permitir el acceso de 
quienes pretendan asistir a ellos, los profesionales de la información tendrán derecho preferente.- 2. La información que pueda derivarse de los actos a que se refiere el párrafo anterior $y$, en general, de los asuntos de la competencia del Tribunal, se efectuará por el Gabinete Técnico del Tribunal Supremo y en la correspondiente Sala de Prensa. 3. No se permitirá el acceso con cámaras fotográficas, de vídeo o televisión al Palacio del Tribunal Supremo, salvo a los actos de apertura del a_o judicial tomas de posesión y otros gubernativos solemnes».

Ante una queja de la Asociación de la Prensa de Madrid, la Sala de Gobierno del Tribunal Supremo, en sesión de 5 de octubre de 1995, adoptó el siguiente nuevo Acuerdo:

«La Sala de Gobierno considera que la Norma Sexta de las que rigen el acceso al Palacio sede del Tribunal Supremo, aprobada en su sesión de 25 de septiembre último, no sólo no coarta el derecho a la información y el acceso al Tribunal de quienes profesionalmente lo sirven, sino que lo potencia y favorece dispensando a éstos un trato de privilegio; que respeta la publicidad de juicios y vistas y la presencia en ellos de los medios de información con útiles de escritura o grabación, sin más condicionamientos que los mínimos de seguridad e identificación comunes a todo profesional o visitante del Palacio; y que la exclusión de los medios visuales, en línea con el criterio seguido en países de nuestro entorno cultural, con la quizá única excepción de Italia, además de constituir un tema de afectación general a todas las Salas del Tribunal y no una cuestión particular de cada una de ellas, obedece a principios de dignidad y garantía, exigentes de que juicios y vistas se celebren en un marco de seriedad, con respeto al Tribunal y a quienes intervienen ante él, eliminando toda connotación de espectáculo y sin tensiones o presiones que puedan alterar la serenidad y reposo convenientes de quienes declaran o informan, poniendo en riesgo su libertad de expresión o derecho de intimidad e imagen. Consecuentemente, mantiene y confirma la referida norma sexta y dispone que así se comunique a la Asociación de Prensa de Madrid suscritora del escrito considerado».

Habiendo interpuesto la Federación de Asociaciones de la Prensa de España y un grupo de periodistas de tribunales sendos recursos ordinarios contra los indicados acuerdos de la Sala de Gobierno del Tribunal Supremo, por considerarlos nulos por vulnerar la Constitución, por haber sido dictados por órgano manifiestamente incompetente por razón de la materia, por lesionar el contenido esencial de derechos y libertades susceptibles de amparo constitucional y por falta de la necesaria motivación y notificación a los interesados, el Pleno del C.G.P.J., por Acuerdo de 7 de febrero de 1996, desestima los recursos, entendiendo que no existe vulneración del derecho de información y del principio de publicidad de los juicios y que la prohibición de la presencia de la prensa gráfica y de la televisión en los actos judiciales públicos «encuentra plena justificación también en el deber de asegurar a todos los que participan en tales actos (partes, peritos, testigos, abogados, e incluso el propio Tribunal), que sus cometidos podrán desarrollarse serenamente, sin presión alguna» y no resulta discriminatoria.

No obstante, como «las normas generales de utilización del edificio dictadas por la Sala de Gobierno en el ejercicio de su competencia de organización y buen gobierno del edificio, están subordinadas a las que en el ejercicio de su función jurisdiccional puedan adoptar las Salas de Justicia en garantía del principio de 
publicidad de los juicios", se estiman parcialmente los recursos respecto del contenido del punto 3_ de la norma 6_ de las aprobadas por la Sala de Gobierno del Tribunal Supremo el 25 de septiembre de 1995 (acceso con cámaras fotográficas, de vídeo o televisión), «... en la medida en que tal cláusula no respeta las facultades jurisdiccionales de las Salas para autorizar en cada caso el acceso de medios audiovisuales a las vistas, quedando vigente en el aspecto gubernativo que afecta al régimen general de acceso al Palacio sede del Tribunal Supremo". (Francisco Bueno Arus. Estudios sobre el Código Penal de 1995. Consejo General del Poder Judicial)."

\section{6.- Función divulgativa y pedagógica del periodismo de tribunales}

Hablar de la justicia en los medios de comunicación es contar cómo funcionan los tribunales de justicia a los ciudadanos de una forma gratuita para la administración de justicia y ayudando al ciudadano a comprender el ordenamiento jurídico, cumpliendo una función social para el público.

Las plataformas digitales de televisión con canales que retransmiten los juicios o la actividad judicial aunque sea de forma "fría" divulgan la información judicial a la opinión pública interesada en estas noticias.

Aunque también se pueden realizar otras experiencias comunicativas como la que llevó a cabo Canal Sur Radio (la Radio Autonómica de Andalucía) ${ }^{7}$ de forma pionera en España con la aparición del tribunal del jurado.

Se emitieron durante una temporada varios programas sobre un juicio con un jurado en directo en esta cadena de radio que tuvo bastante audiencia y repercusión social, donde participaban jueces, fiscales y abogados en ejercicio profesional.

El programa consistía:

1. Se narraba el delito por un presentador con efectos de sonido.

2. Después intervenían las partes y se iba explicando el mecanismo de estos juicios con jurado. Los miembros eran oyentes que estaban en diferentes emisoras de Andalucía.

3. Al final se emitía el veredicto.

Este tipo de programación desde una radio pública contribuyó a divulgar el tribunal del jurado entre todos los oyentes de Andalucía.

También esta radio, pero en la cadena Radio Andalucía Información, emite un programa semanal de información judicial para toda la Comunidad de Andalucía denominado $\boldsymbol{E} \boldsymbol{L} \boldsymbol{B} \boldsymbol{F E T E}$, sobre contenidos jurídicos destinados a la opinión pública en general. Por ejemplo:

- La figura del fiscal. Se entrevista a un fiscal y se explica su trabajo.

- Cambios de nombres. Lo explica un magistrado del Registro Civil.

7 Consultar Fonoteca de Canal Sur Radio (Programas), Pabellón de Canal Sur, Isla de la Cartuja 41092, Sevilla. 
- ¿Quién puede ser miembro de un tribunal del Jurado? El secretario de la Oficina del Jurado ofrece de una forma clara esta respuesta ${ }^{8}$.

\section{Bibliografía:}

- AA.VV.: Manual de Periodismo Judicial. Ámbitos para la Comunicación, Grupo de Investigación en Estructura, Historia y Contenidos de la Comunicación, Universidad de Sevilla, Colegio de Abogados de Sevilla, 2000.

- AA.VV.: Los Sucesos El País. Ediciones El País, Madrid, 1996.

- AA.VV.: Libertad de Expresión y Medios de Comunicación. Poder Judicial, n. especial 13, Consejo General del Poder Judicial, Madrid, 1990.

- AA.VV.: Congreso de Derecho Penal y Procesal <El nuevo Código Penal y la Ley del Jurado>, AA.VV. Fundación El Monte y Universidad de Sevilla, Sevilla 1998.

- BARROSO GARCÍA, Jaime: Proceso de la información de actualidad en televisión. Instituto Oficial de Radio Televisión Española (IORT), RTVE, Madrid, 1993.

- BERDUGO GÓMEZ DE LA TORRE, Ignacio: Honor y Libertad de Expresión. Tecnos, Madrid 1987.

- CARRILlO, Marc: Los límites a la libertad de prensa en la Constitución Española de 1978. Editorial P.P.U., Barcelona, 1987.

- DE CARRERAS, Luis: Presidente del Consejo Audiovisual de Cataluña, Conferencia: Televisión y Juicio Penal: La autoregulación como alternativa a las restricciones legales informativas y como sistema de relación entre las televisiones y los jueces, en el Encuentro entre jueces y periodistas (Federación de Asociaciones de la Prensa y Consejo General del Poder Judicial), Madrid, octubre de 1998.

- DE ROBLES, Federico: Conferencia: "Relaciones de los periodistas con la administración de justicia en el Seminario": El periodista ante la información judicial, Sevilla, 14 de diciembre de 1996.

- FERNÁNDEZ MIRANDA CAMPOAMOR, Alfonso: El secreto profesional de los informadores. Tecnos. Madrid, 1990.

- GARCÍA AVILÉS, José Alberto: Periodismo de Calidad: Estándares informativos en la $C B S, N B C$ y $A B C$. Ediciones Universidad de Navarra S.A.,Pamplona 1996.

8 Consultar Fonoteca de Radio Andalucía Información,, Pabellón de Canal Sur, Isla de la Cartuja 41092, Sevilla. 
- LEÑA FERNÁNDEZ, Rafael: La imposible defensa del honor en la publicación mediática de los procesos penales. Discurso de ingreso en la Real Academia Sevillana de Legislación y Jurisprudencia. Sevilla, 1997.

- QUESADA, Montserrat: La Investigación Periodística. El caso español. Editorial Ariel S.A. Barcelona 1987.

- RODRÍGUEZ, Pepe: Periodismo de Investigación: técnicas y estrategias. Ediciones Paidós Ibérica, Barcelona, 1994.

- RONDA IGLESIAS, Javier: El trabajo del periodista de tribunales, entre la noticia y el juzgado. Conferencia en el Curso de Periodismo Judicial, Universidad Autónoma, Consejo General del Notariado, El País, 24 de junio de 2002, Madrid.

- TIMOTEO ÁlVAREZ Jesús: Historia y Modelos de la Comunicación en el Siglo XX. El nuevo orden informativo. Ariel Comunicación S.A., Barcelona 1992.

- WARREN CARL, N.: Géneros Periodísticos Informativos. Colección Libro de Comunicación Social, ATE, Barcelona 1979.

- YANEL, Agustín: Conferencia: "Demasiadas carencias para un derecho fundamental", redactor de tribunales del diario El Mundo en Encuentro entre jueces y periodistas (Federación de Asociaciones de la Prensa y Consejo General del Poder Judicial), Madrid, octubre de 1998.

- ZARZALEJOS NIETO, José A.: Conferencia: "Estrategias de la crónica judicial", Director Editorial del Grupo Correo en el Encuentro entre jueces y periodistas (Federación de Asociaciones de la Prensa y Consejo General del Poder Judicial), Madrid, octubre de 1998. 